\title{
Extended numerical modeling and application of the coaxial shear test for asphalt pavements
}

\author{
K. Sokolov, R. Gubler and M. N. Partl \\ Empa, Swiss Federal Laboratories for Materials Testing and Research, Laboratories for Road Engineering / Sealing \\ Components, Überlandstrasse 129, CH-8600 Dübendorf, Switzerland
}

Received: 8 November 2004; accepted: 2 February 2005

\begin{abstract}
Coaxial Shear Test (CAST) is used at EMPA road engineering center for determining the mechanical properties of asphalt concrete under repeated sinusoidal loading in both load and strain controlled mode at different temperatures and frequencies. CAST provides stiffness information under lateral deformation confinement, thus simulating the situation in a pavement layer under an idealized traffic loading. In order to understand the complex behavior of the system, Finite Element Analysis (FEA) of the complete test setup was carried out. The details of the FEA model as well as the data analysis procedure are described. New types of experiments, carried out with the CAST equipment, such as the determination of the water sensitivity under combined cyclic mechanical and temperature loading, are described. The distinctive features of the implementation and evaluation of the mechanical properties from experiments are discussed.

1359-5997 (C) 2005 RILEM. All rights reserved.

\section{RÉSUMÉ}

L'essai de cisaillement coaxial (CAST) est utilisé à l'EMPA pour déterminer les propriétés mécaniques des mélanges bitumineux compactés sous charge sinusoïdale alternée avec contrôle de la charge ou du déplacement à des températures et des fréquences différentes. L'essai CAST fournit des informations sur la rigidité sous contrainte de déformation latérale simulant la situation de l'enrobé sous une charge de trafic idéalisée Pour mieux comprendre le comportement complexe du système, une analyse par éléments finis (FEA) de la géométrie de l'essai complet a été effectuée. Les détails du modèle FEA et les procédures nécessaires pour traiter les données sont discutés. De nouveaux types d'essais utilisant l'équipement CAST, comme la détermination de la susceptibilité à l'eau sous chargement cyclique et avec variation cyclique de la température sont décrits. Le principe de l'implémentation et la méthode d'évaluation des propriétés mécaniques à partir d'essais sont discutés.
\end{abstract}

\section{INTRODUCTION}

The CoAxial Shear Test CAST is a performance oriented mechanical test method which has been designed to reflect both traffic loading conditions and the complex stress-strain response within flexible bituminous road pavement layers. The loading direction is the same as on the road, i.e. vertically to the layers.

CAST is a test where a ring shaped specimen with an outer and inner diameter of $150 \mathrm{~mm}$ and $55 \mathrm{~mm}$ is glued between a steel ring and a steel core (Figs. 1 and 2). Load in axial direction is applied by means of a steel rod which is connected to the steel core in the center of the specimen.
Hence, the lateral surface of the cylindrical specimen is deformation and rotation constrained in the radial direction as it is the case for the loaded part of the road under the wheel with similar geometry. Though the loading is sinusoidal, the test differs from both uniaxial and conventional triaxial tests in its way of lateral deformation confinement which is imposed by the steel ring.

CAST is a versatile tool to determine mechanical properties of bituminous road materials. The test setup can easily be adopted to simulate combined climatic and traffic loading of a road in a well defined way and often better than with other tests. It allows investigating laboratory produced specimens and cores. Testing of the cores can be done without eliminating

\footnotetext{
Editorial note

EMPA is a RILEM Titular Member. Dr. Manfred N. Partl is a RILEM Senior Member and a member of the RILEM Technical Activities Committee (TAC). He is the Chairman of RILEM TC ATB 'Advanced testing and characterization of bituminous materials' and also participates in RILEM TCs 197-NCM 'Nanotechnology in construction materials' and CAP 'Cracking in Asphalt Pavements'. Mr. Remy Gubler participates in the above-mentioned RILEM TC ATB.
} 


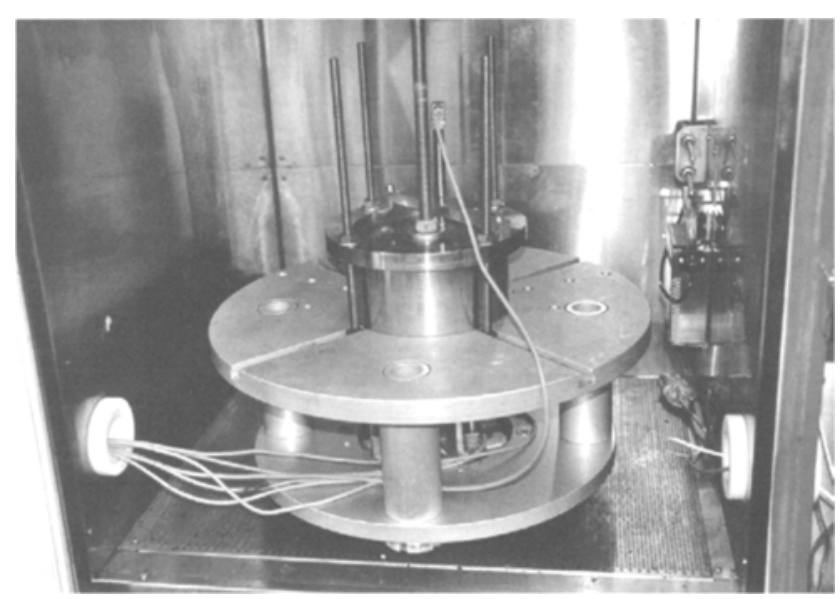

Fig. 1 - CAST setup inside the climatic chamber and connected to the servo hydraulic loading system.

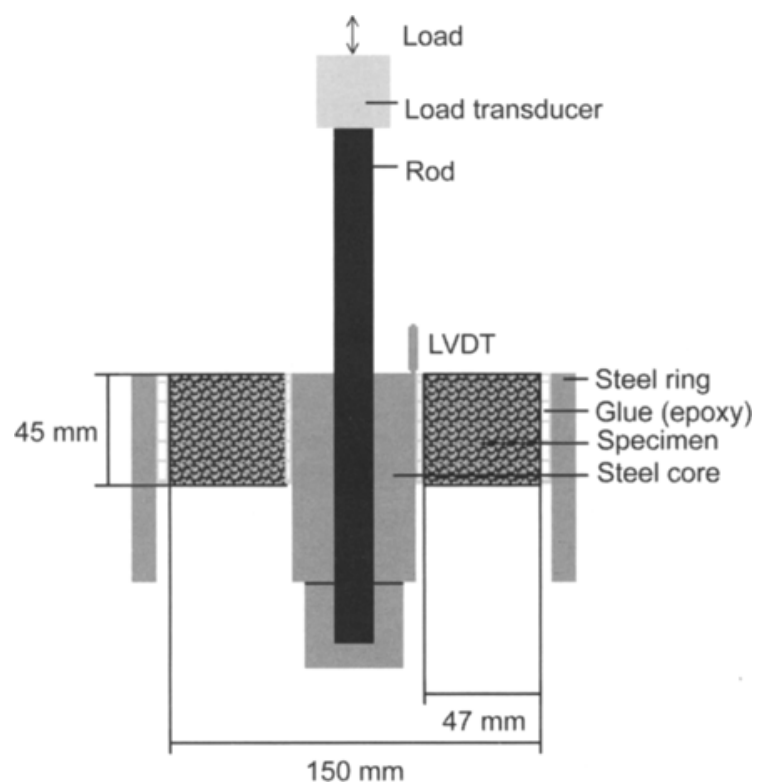

Fig. 2 - Principle of the CAST test setup.

the influence of the original surface on the mechanical properties. Such influence could be induced by surface damage such as cracks or raveling. It allows studying materials in a wide range of temperatures without disturbing the specimen's response to loading by permanent deformation or relaxation effects at clamping.

While, as shown below, CAST methodology has now reached a quite advanced state of development which allows to use the advantages of the test in a rather easily and more successful way, older approaches of the mathematical treatment and modeling were not fully satisfying.

\section{PREVIOUS STUDIES}

Finite element analysis of the CAST testing system was applied in earlier studies using 2D and later 3D Finite Element Analysis (FEA) models [1-3]. In [1] and [2] only a 2D analysis was carried out. The 3D model in [3] included only specimen, steel ring, steel core and the glue (Fig. 2). The possible influence of the supporting aluminum construction (Fig. 1) on the overall behavior of the tested specimen as well as special features of the contact between the glue cylinders and the steel parts were not investigated. Nonlinear behavior was not taken into account either.

In [3], selected results were also compared with other tests in a RILEM interlaboratory test [4] assuming that the relation between complex shear modulus $\mathrm{G}^{*}$ and Young's modulus $E^{*}$ can be taken as

$$
E^{*}=2 \cdot(1+v) \cdot G^{*}=3 \cdot G^{*}
$$

This relation is valid for an incompressible material (Poisson's ratio $v=0.5$ ) and a linear behavior. The RILEM interlaboratory tests with asphalt concrete showed reasonable agreement at a low temperature of $0^{\circ} \mathrm{C}$ but non negligible differences at higher temperatures of $20^{\circ} \mathrm{C}$ i.e. lower frequencies (Fig. 3)

In addition, Electronic Speckle Pattern Interferometry (ESPI) was used to measure the actual deflection basin on the surface of a CAST specimen during loading [3], and the FEA calculations were compared to the real ESPI results, showing acceptable correspondence for the tested material in a given case.

In all these FEA considerations, it was assumed that the modulus is directly proportional to the ratio between applied force and displacement along the steel core. In terms of Young's modulus this reads

$$
E^{*}=\frac{F_{a}}{\delta_{a}} \cdot C_{F E}
$$

where

$E^{*}$ : Complex Young's modulus;

$F_{a}$ : Force amplitude along the steel core;

$\delta_{a}$ : Displacement amplitude along the steel core;

$C_{F E}$ : Coefficient of proportionality derived from FEA.

It was further assumed that the coefficient $C_{F E}$ depends exclusively on the geometry of the specimen such as inner diameter, outer diameter and height.

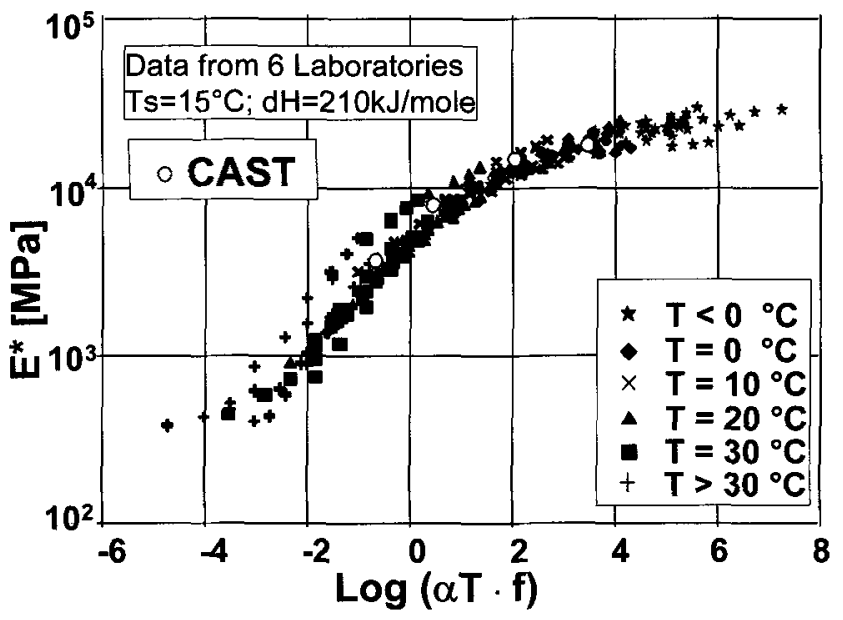

Fig. 3 - CAST results compared to master curves from bending of an asphalt concrete in a RILEM interlaboratory test [4]. 


\section{OBJECTIVES}

For improved modeling of the CAST testing system, the following FEA investigations were carried out in this study:

- The complete test setup included the aluminum supporting construction was modeled. The results were compared to the previous results given in [3].

- The influence of the contact zone between the glue and the steel parts on the mechanical response of the asphalt specimen was numerically investigated.

- A series of the FEA calculations was carried out to clear up the dependence of the coefficients $C_{F E}$ on material stiffness (i.e. the Young's modulus).

- In order to locate damage initiation during repeated loading, the most deformed elements in the asphalt specimen during the CAST test were determined.

\section{FINITE ELEMENT ANALYSIS}

\subsection{Methodical aspects}

The software program ABAQUS, version 6.3 [5], was used for all finite element calculations. The ABAQUS internal three-dimensional continuum stress/displacement elements of type C3D6 (6-node linear triangular prism) and C3D8 (8-node linear brick) were used for the whole construction, see Fig. 4 . Only the elements of type C3D8 were used for the asphalt specimen. A quarter of the whole construction was modeled due to symmetry, and the symmetric boundary conditions were prescribed on the cut-off surface. The boundary condition in the contact zone between the bottom aluminum plate and the ground steel plate was modeled as a single contact line with one rotational degree of freedom. The overall load applied to the CAST specimen through the load transducer and the steel road (Fig. 2) was modeled as concentrated vertical point loads applied to the nodes on the upper surface of the steel core.

Table 1 shows the material parameters used for the FEA calculations. The Poisson's ratio was set to $v=0.38$, a value typical for compacted asphalt and in the middle of a range given in [6].

The standard linear static solver of ABAQUS was used for the finite element calculations presented in this publication. Other results achieved for the chosen model with the nonlinear standard solver and the explicit dynamical solver, including the dynamical response of the CAST structure and the investigation of the time and temperature dependent material nonlinearity will be presented elsewhere.

The results are the $C_{F E}$ coefficients used in Equation (2). They depend on the specimen's thickness, the outer and inner radius. However, contrary to the previous studies, the $C_{F E}$ coefficients also depend clearly on the modulus of the asphalt pavement material. Table 2 summarizes the values of the varied parameters. The $C_{F E}$ coefficients are located in a four dimensional space with these parameters as axis. They are stored in a master table for computational use and interpolation (see below).

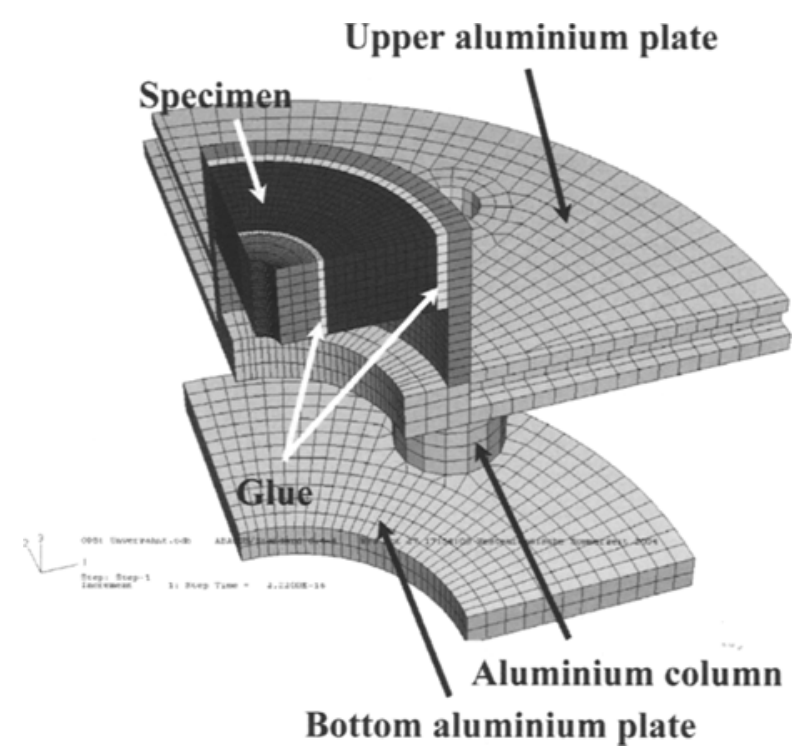

Fig. 4 - Complete finite element FEA model of the CAST, quarter of the whole system including the supporting construction.

\begin{tabular}{|c|c|c|c|}
\hline \multicolumn{4}{|c|}{ Table 1 - Material parameters used in the FEA } \\
calculations \\
\hline Material & $\begin{array}{c}\text { Construction } \\
\text { parts }\end{array}$ & $\begin{array}{c}\text { Young's } \\
\text { modulus [MPa] }\end{array}$ & $\begin{array}{c}\text { Poisson's } \\
\text { ratio }\end{array}$ \\
\hline Aluminium & $\begin{array}{c}\text { Supporting } \\
\text { construction }\end{array}$ & 60000 & 0.34 \\
\hline Steel & Ring and core & 200000 & 0.33 \\
\hline Epoxy & Glue cylinders & 2000 & 0.38 \\
\hline Asphalt & Specimen & $\begin{array}{c}100,1000,5000, \\
10000\end{array}$ & 0.38 \\
\hline
\end{tabular}

\begin{tabular}{|l|l|}
\hline \multicolumn{2}{|c|}{ Table 2 - Variation of geometry and stiffness } \\
\hline Varied value & Set of values \\
\hline Thickness [mm] & $30,35,40,45,50,55,60$ \\
\hline Diameter of specimen [mm] & $141,145,149,153,157$ \\
\hline Diameter of central hole [mm] & $51,54,57,60$ \\
\hline Complex modulus [GPa] & $0.1,1,5,10,25$ \\
\hline
\end{tabular}

\subsection{Investigated influence parameters}

The influence of the load direction (downward, upward) on the mechanical behavior of the CAST specimen was studied in a preliminary FEA calculation but was found of minor importance (maximum relative differences for stresses and deformations less then $0.5 \%$ ). Hence, all subsequent FEA calculations were carried out for the downward direction of the load.

The influence of the contact zone between the glue and the steel parts on the mechanical response of the asphalt specimen was also taken into account. The fluted surfaces of the steel core and steel ring as well as the appropriate grooves on the inner cylindrical surface of the inner glue layer and on the outer cylindrical surface of the outer glue layer were modeled accurately in every detail. A preliminary finite element calculation showed that these surface effects are of minor influence on the mechanical behavior of the specimen 


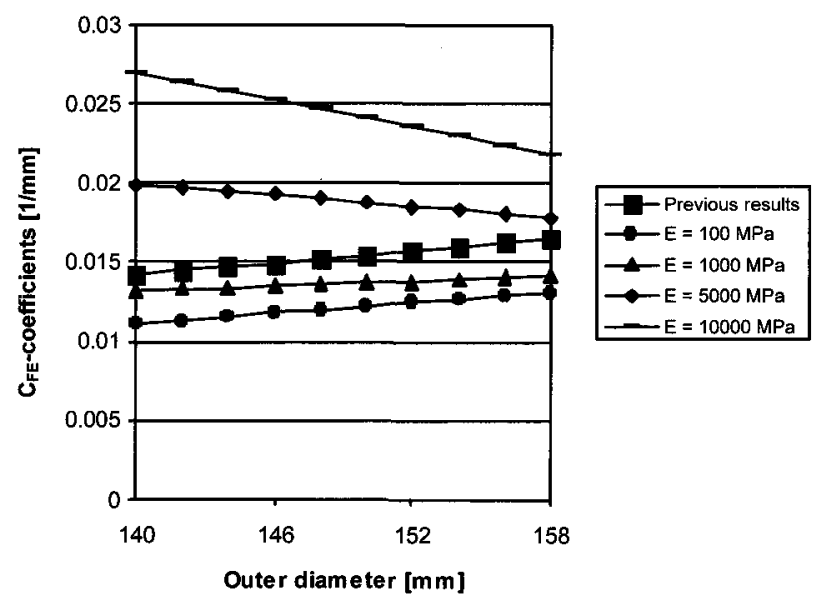

Fig. 5 - Comparison between previous and new FEA results: coefficients $C_{F E}$ for specimen height $50 \mathrm{~mm}$, specimen inner diameter $54 \mathrm{~mm}$.

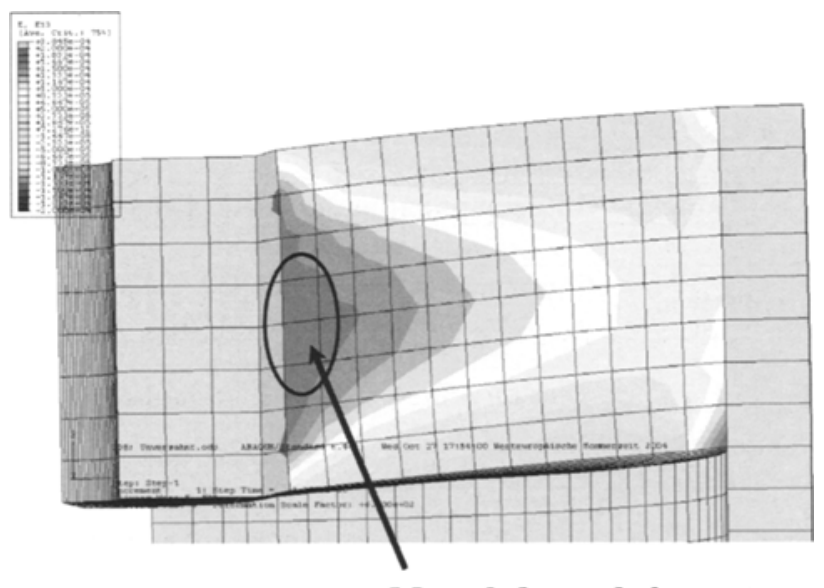

Most deformed elements

Fig. 6 - Localisation of the most deformed area of the specimen, contour plot for deformation $\varepsilon_{13}$.

(maximum differences for the strain values inside the specimen come to $1 \%$ ). For that reason all cylindrical borders of the glue layers and steel parts were modeled as smooth surfaces "soldered" together in contact zone.

\subsection{Comparison to the previous results}

As mentioned above the finite element coefficients $C_{F E}$ were assumed in previous investigation [3] to be geometrical constants independent of material properties. The data shown in Fig. 5 are the results of the previous work (calculated for the case $E^{*}=1000 \mathrm{MPa}$ ) and the new results for different values of $E^{*}$. As it is evident from this figure, the effect of $E^{*}$ on the coefficients $C_{F E}$ is very important which is mainly due to the glue asphalt interaction. It can be also seen that the old and new results for $E^{*}=1000 \mathrm{MPa}$ diverge from each other slightly. This is because a smaller value of the Poisson's ratio was used for new calculations, and the mechanical response of the weak aluminum supporting construction of the CAST testing system was taken into account.

\subsection{Most deformed elements}

Failure is closely linked to deformation. This holds true for fatigue tests as well as for cases of loading exceeding the viscoelastic linearity limits [6-8]. For a better understanding of the system, the area of the maximum deformation according FEA was determined (Fig. 6). The function $\mathrm{S}(\mathrm{E})$ explained below allows calculating the shear strain of this area throughout a whole test.

\section{FEA-MODEL IMPLEMENTATION}

\subsection{Goal}

The goal of the implementation is to develop a tool that allows calculating the complex modulus as well as other interesting properties for any given geometry from raw data (measured force $F$ and displacement $\delta$ of the central steel core). This would be an easy task, if the relation between the calculated displacement and the geometrical constants as well as the material property was linear. Given that, a simple interpolation in a four dimensional space or using a system of linear equations obtained by regression would give the desired result.

\subsection{Investigation of the system behavior}

\subsubsection{Linearity of the system}

The first step was to determine the nature of the system consequently. This can be done by inspecting any local element with respect to its linear behavior. Since repetition of the modulus measurement on the same specimen normally scatters 2 to $3 \%$, deviation of linearity should be below $1 \%$. Since only few selected cases showed low deviations, nonlinear behavior was found predominant. Fig. 7 shows that the coefficient $C_{F E}$ is nearly exactly linearly dependent of the specimen's outer radius. However, as Fig. 8 demonstrates, this is not the case for the specimen's inner radius. The attempt to use the inverse of the inner radius resulted also in a nonlinear relationship. Since nonlinear behavior was also observed regarding the modulus (see Fig. 9), the linear approach was completely abandoned.

\subsubsection{The modulus function}

In the classic approach valid in a linear system, the modulus can be calculated from the amplitudes of force and deformation using a coefficient $C_{F E}$ derived from FEA according to Equation (2). In the nonlinear case, valid for the CAST, the geometrical constant $C_{F E}$ has to be replaced by a function $A(E)$ of the modulus itself (Equation (3)).

$E^{*}=\frac{F_{a}}{\delta_{a}} \cdot A\left(E^{*}\right)$

where

$A\left(E^{*}\right)$ : Coefficient function

$E^{*}: \quad$ Modulus

$F_{a}: \quad$ Amplitude of force

$\delta_{a}$ : Amplitude of displacement of the central core 


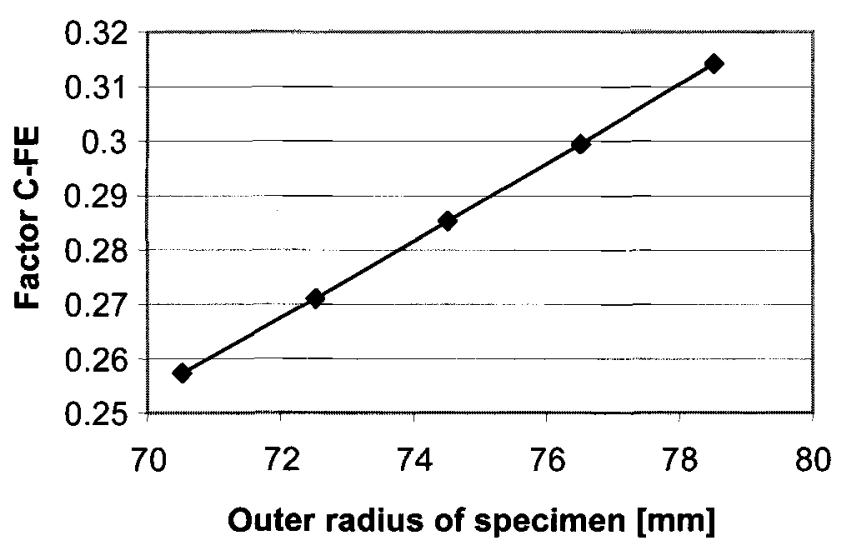

Fig. 7 - Dependence of the coefficient CFE from the specimen's outer diameter for a selected case.

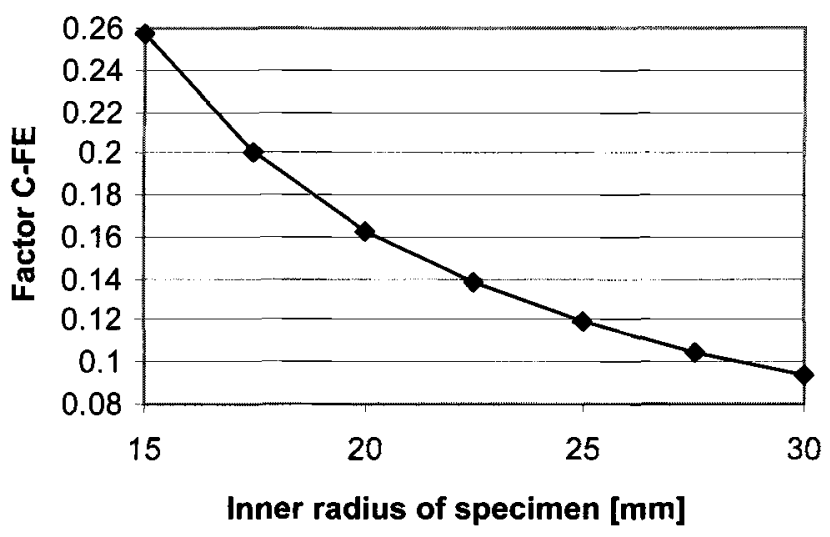

Fig. 8 - Dependence of the coefficient CFE from the specimen's inner radius for a selected case.

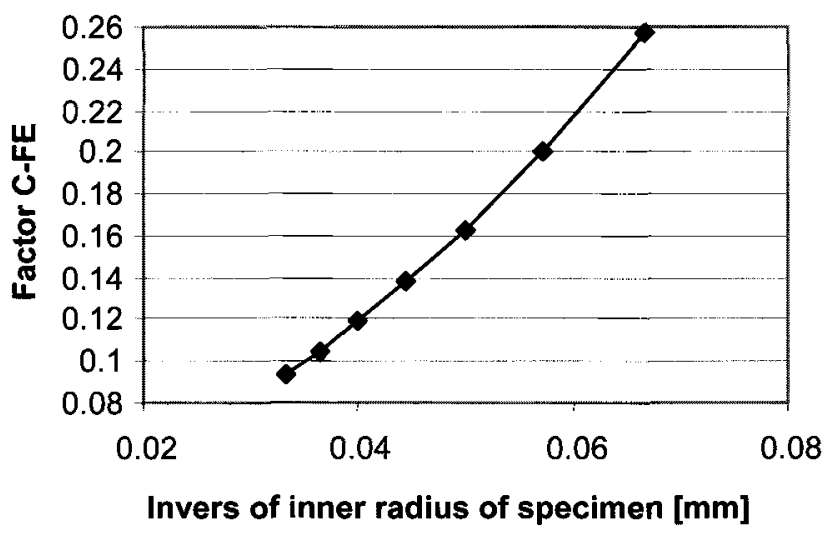

Fig. 9 - Example of modulus function $A(E)$ using selected case of geometrical parameters.

Investigation showed that the function can be defined as shown in Equation (4), $A_{1}, A_{2}$ and $A_{3}$ now functions of the specimen's geometry.

$$
A\left(E^{*}\right)=A_{1}+A_{2} \cdot E^{* A 3}
$$

where
$A\left(E^{*}\right)$ :
Coefficient function

$E^{*}:$ Modulus

$A 1, A 2, A 3$ : Constants depending on geometry only

\begin{tabular}{|c|c|c|c|}
\hline \multicolumn{4}{|c|}{ Table 3 - Back calculation of the modulus using the } \\
nonlinear approach \\
\hline $\begin{array}{c}\text { Displacement } \\
\text { [mm] }\end{array}$ & $\begin{array}{c}\text { Expected } \\
\text { modulus } \\
\text { [GPa] }\end{array}$ & $\begin{array}{c}\text { Back } \\
\text { calculated } \\
\text { modulus } \\
\text { [GPa] }\end{array}$ & Deviation [\%] \\
\hline 0.2575 & 0.1 & 0.0991 & -0.90 \\
\hline 0.03087 & 1 & 1.006 & 0.60 \\
\hline 0.009123 & 5 & 4.993 & -0.14 \\
\hline 0.005909 & 10 & 10.006 & 0.06 \\
\hline 0.003638 & 25 & 24.999 & 0.00 \\
\hline
\end{tabular}

Inserting Equation (4) into (3) creates a recursive Equation (5) with $E^{*}$ on both sides. This equation cannot be solved analytically but by iteration based on (5) using a starting value $E^{*}$ to calculate the resulting value $E_{r}{ }_{r}$.

$$
E_{r}^{*}=A\left(E^{*}\right) \cdot \frac{F_{a}}{\delta_{a}}=\left(A 1+A_{2} \cdot E^{*}{ }_{s}^{A 3}\right) \cdot \frac{F_{a}}{\delta_{a}}
$$

Substituting $E^{*}{ }_{r}$ as new $E_{s}^{*}$, the calculation can be repeated until $E_{r}^{*}$ is reasonably close to $E^{*}{ }_{s}$. For example, starting with $E_{s}^{*}=10 \mathrm{GPa}$, twenty steps proved sufficient to calculate precise modulus values. Table 3 shows the back calculation based on Equation (5) using coefficients $A_{1}, A_{2}$ and $A_{3}$ obtained by a best fit procedure described below.

\subsubsection{Displacement and Shear Strain Functions}

The function $d_{a}\left(E^{*}\right)$ of the specimen, defined as relative displacement of its inner cylindrical surface in respect to the outer, is an important property of the system (Note, that $d_{a}$ is not identical to the absolute displacement $\delta_{a}$ which is measured along the steel core). It was found that the deformation of the asphalt specimen can be described reasonably well by Equation (6) using another set of constants $\left(D_{l}, D_{2}\right.$ and $\left.D_{3}\right)$.

$$
d_{a}\left(E^{*}\right)=D\left(E^{*}\right) \cdot \frac{F_{a}}{E^{*}}=\left(D_{1}+D_{2} \cdot E^{* D_{3}}\right) \cdot \frac{F_{a}}{E^{*}}
$$

where

$d_{a}\left(E^{*}\right): \quad$ Amplitude of deformation

$E^{*}: \quad$ Modulus

$F_{a}: \quad$ Amplitude of force

$D_{1}, D_{2}, D_{3}$ : Constants obtained by best fit.

Finally, for example in fatigue tests (see [7]), the shear strain in the maximal deformed area is of interest (Fig. 6). This shear strain $\varepsilon_{13}$ can be described by Equation (7).

$\varepsilon_{13}\left(E^{*}\right)=S\left(E^{*}\right) \cdot F_{a}=\left(S_{1}+S_{2} \cdot e^{\left(S_{3}-S 4 \cdot \ln (E)\right)}\right) \cdot F$

where

$\begin{array}{ll}\varepsilon_{13}\left(E^{*}\right): & \text { Shear strain of most deformed FEA element } \\ E^{*}: & \text { Modulus } \\ F_{a}: & \text { Amplitude of force } \\ S_{1}, S_{2}, S_{3}, S_{4}: & \text { Constants obtained by best fit. }\end{array}$




\subsection{Determination of constants by best fit}

The mechanical response data of test specimens (displacement of the central steel core, deformation of the asphalt specimen, deformation of the glue and shear of the most deformed area) are stored in a master table as a function of geometry and modulus of the asphalt. To calculate modulus, deformation and shear strain, as defined above, the constants $A_{1}$ to $A_{3}, D_{1}$ to $D_{3}$ and $S_{1}$ to $S_{4}$ are needed for a specific geometry. As it could be expected from the system's nonlinear behavior (e.g. Fig 8), these constants were found to depend not linearly from the specimen's geometry too. Hence, the points of function like $A\left(E^{*}\right)$ had to be calculated by parabolic interpolation of the master table using the most appropriate local grid of 27 points which is closest to the specimen's geometry. Having three functions $A\left(E^{*}\right), D\left(E^{*}\right)$, and $S\left(E^{*}\right)$ and five modulus values $(0.1,1,5,10$ and $25 \mathrm{GPa})$ implies that 15 such systems have to be solved, using the Gauss-Jordan method.

As a result, the functions $A\left(E^{*}\right), D\left(E^{*}\right)$, and $S\left(E^{*}\right)$ are defined as a list of five values corresponding to the modulus values $0.1,1,5,10$ and $25 \mathrm{GPa}$. However, the coefficients $A_{l}$, $A_{2}, A_{3}, D_{1}, D_{2}, D_{3}, S_{1}, S_{2}, S_{3}$ and $S_{4}$ are needed to calculate the mechanical properties from the raw data for any other modulus. Since the coefficients cannot be deduced analytically from the given information, an iteration procedure has to be used. The attempt to use the solver of the Excel spread-sheet program was not satisfying. In many cases, the solver obviously found a local minimum instead of the global one.

To overcome this problem, an iterative software was developed based on the principle of simulated annealing. A single iteration can be described by the following rules:

- calculate a new set of constants by changing the old one by adding to each constant a step width multiplied by a random number in the range of -1 to +1

- if the new set of constants is better than the old one, find the best set along the line defined by the old and the new one in the mathematical space of the constants

- if the new set is worse, calculate the probability $P$ to accept it nevertheless using Equation (8)

- adapt the threshold T of Equation (8) as well as the step widths according the progress of iteration

- stop iteration if no substantial progress can be made

$P=e^{\left(Q_{i-1}-Q_{i}\right) / T}$

where

$P: \quad$ Probability to accept a set of constants

$Q_{i}: \quad$ sum of square deviations of set $\mathrm{i}$

$Q_{i-1}$ : preceding sum of square deviation of set $\mathrm{i}-1$

T: $\quad$ Threshold

Note, that for $Q_{i}>Q_{i-1}$, the threshold $T$ is controlling to what extend the algorithm allows to proceed to solutions with a higher sum of square deviations in order to escape a local minimum.

Such a single iteration leads with high probability $(>90 \%)$ to a good approximation. In the remaining few cases too high sums of square deviation were found, if using only one single iteration. Thus, the software was written such, that the single iteration was repeated five times to reduce the probability of finding a local instead of a global minimum close to zero. The validity of the coefficients $A_{1}, A_{2}, A_{3}, D_{1}, D_{2}, D_{3}, S_{1}, S_{2}, S_{3}$ and $S_{4}$ is limited to the range of calculated $C_{F E}$ values. For modulus values clearly exceeding the range of 0.1 to $25 \mathrm{GPa}$ the coefficients are no longer valid. Table 3 shows a typical result using the coefficient determined by this procedure.

\section{APPLICATIONS}

This section describes two CAST applications: the basic test to determine the modulus and a sophisticated variant to investigate water sensitivity.

\subsection{Determination of modulus}

Determination of the modulus is a fundamental task in mechanical testing. Other tests, such as fatigue testing, are partly based on the determination of the modulus.

Table 4 shows the test condition typically achieved with the CAST. Loading amplitudes respect the viscoelastic linearity limits as discussed in [8]. Fig. 10 shows the complex modulus, Fig. 11 the master curve. The master curve was calculated using the WLF time-frequency superposition principle and the sigmoidal approach to describe the dependence of the complex modulus from the reduced frequency.

Fig. 10 demonstrates that test temperature and frequency can be varied significantly. It allows the testing of materials with low modulus without serious damaging effect. This is due to the fact that the specimen is well protected within its steel ring. It has to be pointed out that the whole test was done using the same specimen.

\subsection{Determination of water sensitivity under dynamic loading}

This example described in [9] shows that the CAST can easily be modified to simulate field conditions appropriately. Note, that the principle design of the test is important to achieve this. On the one hand, the radial confinement allows executing the test under water easily. On the other hand, damaging by water combined with loading only takes place at a temperature range where specimens without the lateral confinement given by the experimental setup would be seriously damaged by the mechanical loading alone.

A typical temperature regime for the test is shown in Fig. 12. Fig. 13 shows the evolution of the complex modulus, Fig. 14 the corresponding black diagram of a water sensitive material.

\begin{tabular}{|l|l|}
\hline \multicolumn{2}{|c|}{ Table 4 - Test conditions } \\
\hline Designation of condition & Set values \\
\hline Temperatures, low range $\left[{ }^{\circ} \mathrm{C}\right]$ & $-10-5051015$ \\
\hline Temperatures $\left[{ }^{\circ} \mathrm{C}\right]$ & 1520253035 \\
\hline Frequencies $[\mathrm{Hz}]$, both ramps & 0.1250 .250 .51248 \\
\hline Load amplitudes $[\mathrm{kN}]$, low range & 0.3213 .2 \\
\hline $\begin{array}{l}\text { Displacement amplitudes high range, } \\
{[\mathrm{mm}]}\end{array}$ & 0.010 .030 .06 \\
\hline
\end{tabular}




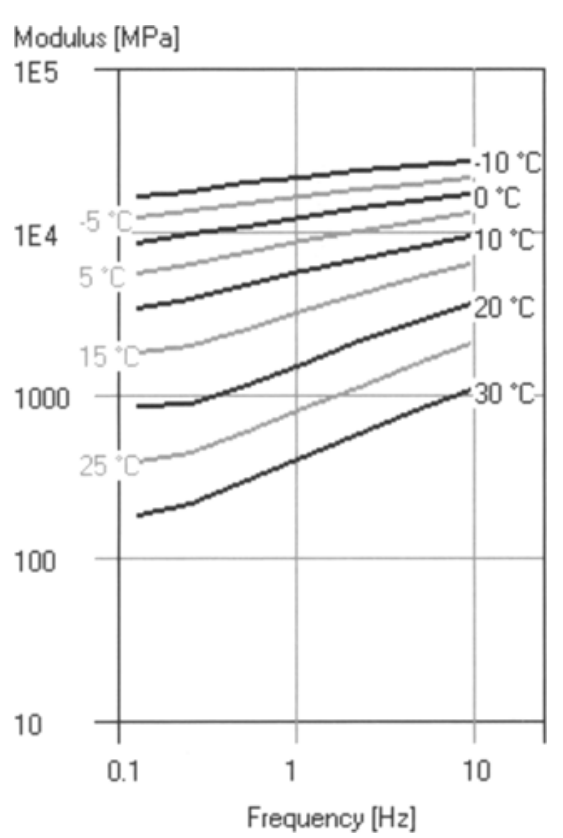

Fig. 10 - Example of the determination of a modulus values of a dense graded asphalt.

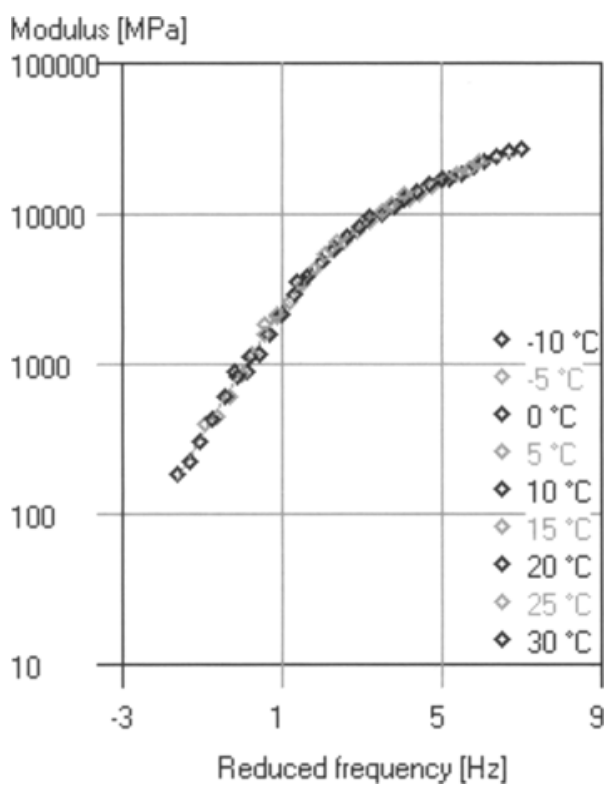

Fig. 11 - Master curve of the specimen in Fig. 10.

\section{CONCLUSION}

- The CAST test can be described mathematically with sufficient precision

- The numerical modeling of the CAST is an interesting example of dealing with a complex experimental setup

- The CAST test is a valuable and versatile tool for research, which can be used for modulus determination and water sensitivity studies

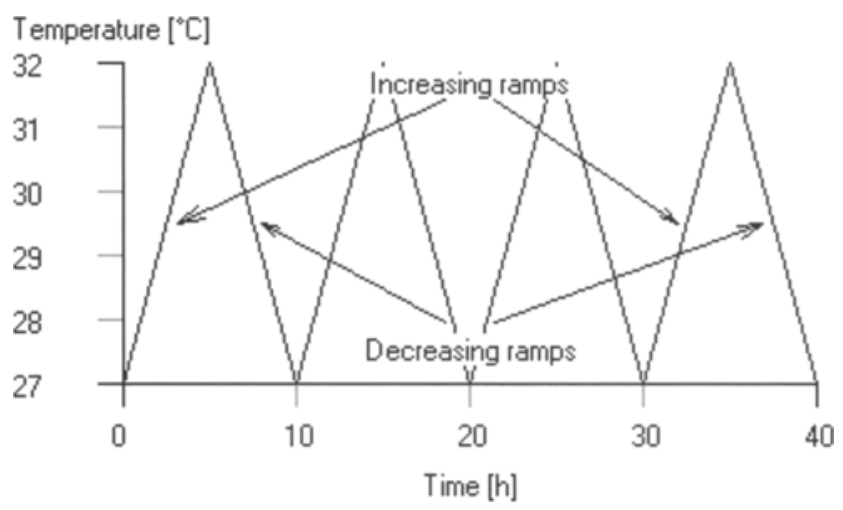

Fig. 12 - Temperature regime during a typical test.

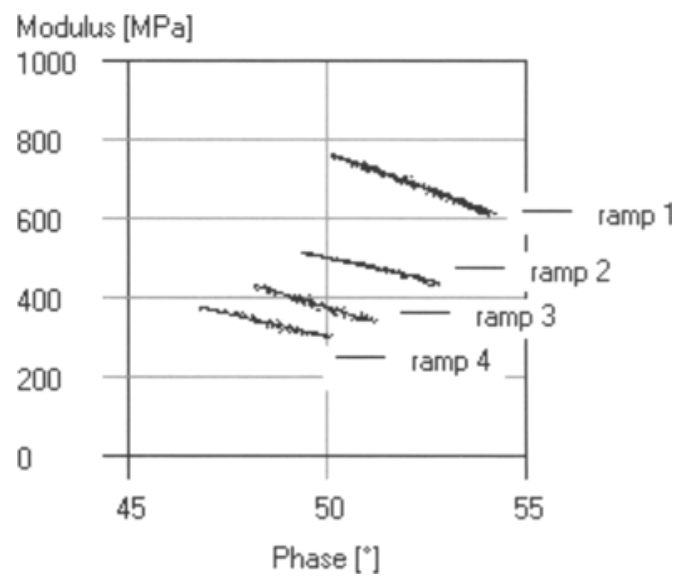

Fig. 13 - Example of a fatigue curve.

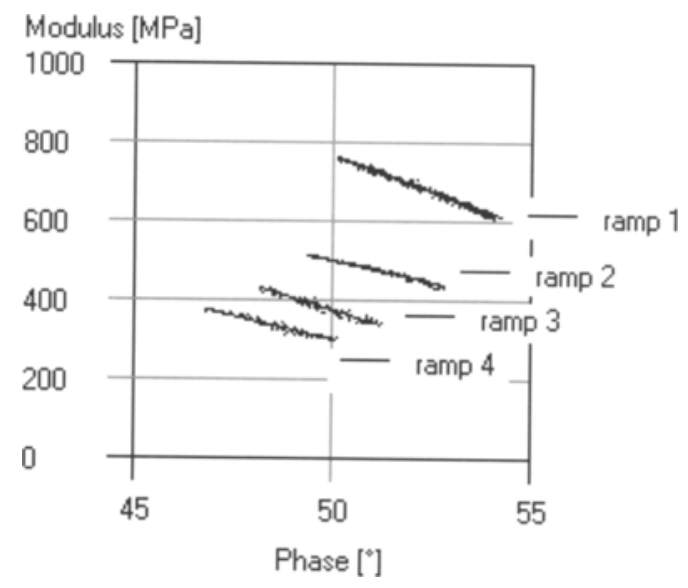

Fig. 14 - Important decrease in the modulus for temperature ramps 1 to 4 of a water sensitive material.

- It can be used to assess the properties of cores from the road applying the same loading vectors as on the road.

- The test can be easily adapted to simulate processes in a pavement that cannot be assessed by other test.

\section{REFERENCES}

[1] Junker, J.P., Fritz, H.W. and Partl, M.N., 'Determination of mechanical properties of bituminous construction materials 
(Bestimmung mechanischer Materialkennwerte an bituminösen Baustoffen)', Eidgenössisches Verkehrs- und Energiewirtschaftsdepartement, Bundesamt für Strassen (ASTRA), Report no. 270, 1993 [in German].

[2] Gubler, R., 'Méthode d'essai par oscillation axiale pour la détermination des caractéristiques mécaniques et du comportement à la fatigue des asphaltes (Axial Vibration Test Procedure to Determine the Mechanical Properties and Fatigue Behaviour of Asphalt)' (RILEM, Chapman and Hall, 1990).

[3] Younger, K.D., Partl, M.N., Fritz, H.W. and Gubler, R., 'Asphalt concrete testing with co-axial shear tester at EMPA', Mechanical Tests for Bituminous Materials, Di Benedetto \& Francken (eds) (RILEM, 1997) 189-195.

[4] Francken, L. and Verstraeten, J., 'Interlaboratory test program on complex modulus and fatigue', RILEM Report 17 Bituminous Binders and Mixtures, TC 152-PBM, edited by L. Francken (E \& FN Spon, ISBN 041922870 5) 181-215 (1998).
[5] ABAQUS Standard User's Manual, Version 6.3, Volume II, Hibbit, Karlsson \& Sorensen, Inc., 2002.

[6] Di Benedetto, H., Partl, M.N., Franken, L. and De La Roche Saint André, C., 'Stiffness testing for bituminous mixtures' Mater. Struct. 34 (March 2001) 66-70.

[7] Di Benedetto, H., De La Roche, C., Baaj, H., Pronk, A. and Lundstöm, R., 'Fatigue on bituminous mixtures', Mater. Struct. 37 (April 2004) 202-216.

[8] Airey, G.D., Rahimzadeh, B. and Collop, A.C., 'Viscoelastic linearity limits for bituminous materials', Mater. Struct. 36 (December 2003) 643-647.

[9] Gubler, R., Baida, L.G. and Partl, M.N., 'A new method to determine the influence of water on mechanical properties of asphalt concrete', International Journal of Road Materials and Pavement Design, Hermes Science Publications, Special Issue EATA (2004) 259-279. 